The Stability of the Mesh-Cornered Synthetic Method of Diffusion Acceleration of the Dot-IV

\title{
Transport Code
}

John Aull

OPERATED BY

UNION CARBIDE CORPORATION FOR THE UNITED STATES DEPARTMENT OF ENERGY 


\section{DISCLAIMER}

This report was prepared as an account of work sponsored by an agency of the United States Government. Neither the United States Government nor any agency Thereof, nor any of their employees, makes any warranty, express or implied, or assumes any legal liability or responsibility for the accuracy, completeness, or usefulness of any information, apparatus, product, or process disclosed, or represents that its use would not infringe privately owned rights. Reference herein to any specific commercial product, process, or service by trade name, trademark, manufacturer, or otherwise does not necessarily constitute or imply its endorsement, recommendation, or favoring by the United States Government or any agency thereof. The views and opinions of authors expressed herein do not necessarily state or reflect those of the United States Government or any agency thereof. 


\section{DISCLAIMER}

Portions of this document may be illegible in electronic image products. Images are produced from the best available original document. 
Printed in the United States of America. Available from National Technical Information Service

U.S. Department of Commerce

5285 Port Royal Road, Springfield, Virginia 22161

NTIS price codes-Printed Copy: A02; Microfiche A01

This report was prepared as an account of work sponsored by an agency of the United States Government. Neither the United States nor any agency thereof, nor any of their employees, makes any warranty, expressed or implied, or assumes any legal liability or responsibility for any third party's use or the results of such use of any information, apparatus, product or process disclosed in this report, or represents that its use by such third party would not infringe privately owned rights. 
Contract No. W-7405-eng-26

Engineering Physics Division

THE STABILITY OF THE MESH-CORNERED SYNTHETIC METHOD OF DIFFUSION ACCELERATION OF THE DOT-IV TRANSPORT CODE

John Aull

Date Published - October 1979

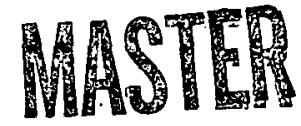

OAK RIDGE NATIONAL LABORATORY

Oak Ridge, Tennessee 37830

operated by

UNION CARBIDE CORPORATION

for the

DEPARTMENT OF ENERGY

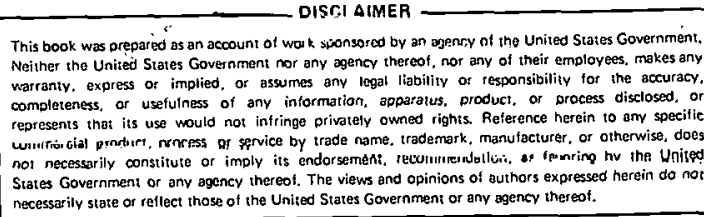




\section{THIS PAGE}

\section{WAS INTENTIONALLY LEFT BLANK}




\section{TABLE OF CONTENTS}

\section{Page}

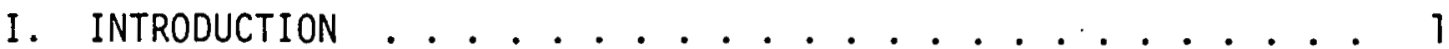

II. CORRECTION EQUATIONS FOR THE THREE METHODS ....... 2

III. STATEMENT OF THE PROBLEM ................ 3

IV. STABILITY ANALYSIS OF THE MESH-CORNERED SYNTHETIC METHOD . . 4

V. NUMERICAL RESULTS AND CONCLUSIONS .......... 7 REFERENCES ................... 11 


\section{THIS PAGE}

\section{WAS INTENTIONALLY \\ LEFT BLANK}




\section{ABSTRACT}

Three methods for accelerating the discrete ordinates equations using variations of the synthetic method are examined. It is found that the use of difference equations written about the mesh corners, rather than a specific form of the equations, brings stability. These methods are compared with three other methods in test problems covering the stability domain of interest. 


\section{INTRODUCTION}

The mono-energetic steady state Boltzmann transport equation in one dimensional slab geometry with isotropic scattering and source is

$$
\mu \frac{\partial}{\partial x} \psi(x, \mu)+\sigma(x) \psi(x, \mu)=\sigma_{S}(x) \phi_{0}(x)+Q(x) .
$$

It can be solved iteratively using

$$
\mu_{m} \frac{\tilde{\Psi}_{m i}^{k}+1 / 2-\tilde{\Psi}_{m i}^{k}-1 / 2}{\Delta x}+\sigma \tilde{\psi}_{m i}^{k}=\sigma_{s} \phi_{0 i}^{k-1}+Q_{i}
$$

and the diamond difference equation,

$$
\tilde{\psi}_{m i}^{k}=\left(\tilde{\Psi}_{m i}^{k}+1 / 2+\tilde{\psi}_{m i}^{k}-1 / 2\right) / 2
$$

Without rebalancing this iteration proceeds as follows:

1. $k=1$.

2. Equations (2) and (3) are solved for $\left\{\tilde{\psi}_{m i}^{k}\right\}$ based on a knowledge of $\left\{\phi_{0 i}^{k-1}\right\}$.

3. $\tilde{\phi}_{0 i}^{k}=\sum_{m=1}^{M} W_{m} \tilde{\psi}_{m i}^{k}$.

4. $\phi_{0 i}^{k}=\tilde{\phi}_{0 i}^{k}$.

5. If $\max _{i}\left|\left[\phi_{0 i}^{k}-\phi_{0 i}^{k-1}\right] / \phi_{0 i}{ }^{k-1}\right|<\varepsilon$ then convergence has been obtained.

6. $K=K+1$.

7. Go to step (2).

With rebalancing, the equation in step (4) of the above procedure is replaced by a correction equation which gives an improved scalar flux, $\phi_{0}^{k}$, based on the unimproved scalar flux, $\tilde{\phi}_{0}^{k}$. The three rebalance methods discussed in this work are different versions of the synthetic method. 
II. CORRECTION EQUATIONS FOR THE THREE METHODS

Reed $^{l}$ investigated the stability of the mesh-centered synthetic correction equation:

$$
\begin{aligned}
& -\frac{D}{(\Delta x)^{2}}\left(\phi_{0 i+1}^{k}-2 \phi_{0 i}^{k}+\phi_{0 i-1}^{k}\right)+\sigma_{R} \phi_{i}^{k} \\
& \quad=-\frac{D}{(\Delta x)^{2}}\left(\tilde{\phi}_{0 i+1}^{k}-2 \tilde{\phi}_{0 i}^{k}+\tilde{\phi}_{0 i-1}^{k}\right)+\sigma_{R} \tilde{\phi}_{0 i}^{k}+\sigma_{s}\left(\tilde{\phi}_{0 i}^{k}-\phi_{0 i}^{k-1}\right)
\end{aligned}
$$

where $\sigma_{R}=\sigma-\sigma_{S}$ and $D=1 / 3 \sigma$.

Alcouffe ${ }^{2}$ used a different formulation on the right-hand side along with mesh-cornered differencing obtaining,

$$
\begin{aligned}
-\frac{D}{(\Delta x)^{2}} & \left(\phi_{0 i}^{k}+3 / 2-2 \phi_{0 i}^{k}+1 / 2+\phi_{0 i}^{k}-1 / 2\right) \\
& +\sigma_{R}\left(\phi_{0 i}^{k}+3 / 2+2 \phi_{0 i}^{k}+1 / 2+\phi_{0 i}^{k}-1 / 2\right) / 4=\frac{1}{2}\left(Q_{i}+Q_{i+1}\right) \\
& -\left[\frac{\tilde{\phi}_{1 j+1}^{k}-\ddot{\phi}_{1 j}^{k}}{\Delta x}\right]-\frac{U}{(\Delta x)^{2}}\left(\dot{\phi}_{0 i}^{k}+3 / 2-2 \phi_{0 i}^{k}+1 / 2+\tilde{\phi}_{0 i}^{k}-1 / 2\right)
\end{aligned}
$$

for the correction equation where the current, $\tilde{\phi}_{1}$, is defined using

$$
\tilde{\phi}_{1 i}=\sum_{m=1}^{M} \mu_{m} w_{m} \dot{\psi}_{m i} .
$$

This method is called the source correction scheme.

This author ${ }^{3}$ helped to develop a method that is similar to the Reed formulation except with mesh-cornered differencing: 


$$
\begin{aligned}
-\frac{D}{(\Delta t)^{2}} & \left(\phi_{0 i}+3 / 2-2 \phi_{0 i}+1 / 2+\phi_{0 i}-1 / 2\right) \\
& +\sigma_{R}\left(\phi_{0 i}+3 / 2+2 \phi_{0 i}+1 / 2+\phi_{0 i}-1 / 2\right) / 4 \\
& =-\frac{D}{\Delta x^{2}}\left(\tilde{\phi}_{0 i}+3 / 2-2 \tilde{\phi}_{0 i}+1 / 2+\tilde{\phi}_{0 i}-1 / 2\right) \\
& +\sigma_{R}\left(\tilde{\phi}_{0 i}+3 / 2+2 \tilde{\phi}_{0 i}+1 / 2+\tilde{\phi}_{0 i}-1 / 2\right) / 4 \\
& +\sigma_{s}\left[\left(\tilde{\phi}_{0 i}-\phi_{0 i}^{k-1}\right)+\left(\tilde{\phi}_{0 i+1}-\phi_{0 i+1}^{k-1}\right)\right] / 2 .
\end{aligned}
$$

It was found that this correction equation can be used consistently when weighted difference methods ${ }^{4}$ are used in the transport calculation in place of Eq. (3).

\section{STATEMENT OF THE PROBLEM}

Reed and Alcouffe have done stability analyses on the synthetic method using, respectively, Eq. (4) and Eq. (5). Reed ${ }^{1}$ found that the condition

$$
\frac{(2 c-1) \sigma \Delta x}{4}<\frac{d}{\Delta x}
$$

(where the scattering ratio, $c=\sigma_{s} / \sigma$ ) is sufficient for convergence for the mesh-centered synthetic method. Numerical testing indicated that this is in fact a necessary condition for convergence with Reed's mesh-centered synthetic method. ${ }^{1}$ Alcouffe found that a sufficient convergence criterion for his source correction scheme (SCS) using Eq. (5) is $c<1$.

The mesh-cornered synthetic method is similar to Reed's method except for the mesh-cornered formulation. It is similar to Alcouffe's SCS except that the right-hand side of Eq. (7) differs from the right side of Eq. (5). 
The questions to be answered in this work are the following. Is the mesh-cornered synthetic method as stable as the SCS method or is it only as stable as the mesh-centered synthetic method? If it is stable then why is it stable?

\section{STABILITY ANALYSIS OF THE MESH-CORNERED SYNTHETIC METHOD}

In this section it is shown that the mesh-cornered synthetic method is as stable as the SCS method.

Reed ${ }^{1}$ showed that if Eqs. (2) and (3) are considered in an infinite slab with zero source then they can be written in the form

$$
\tilde{\phi}_{0}^{k}=M \phi_{0}^{k-1}
$$

where $\tilde{\phi}_{0}^{k}$ and $\phi_{0}^{k-1}$ are vectors of infinite dimension of the form $\left[\ldots, \phi_{0 i-1}, \phi_{0 i}, \phi_{0 i+1}, \ldots\right]^{\top}$. By following Reed's analysis it is a straightforward calculation to show that Eq. (9) can be written using vectors of the form $\left[\ldots, \phi_{0 i}-1 / 2, \phi_{0 i}+1 / 2, \phi_{0 i}+3 / 2, \ldots\right]$. Reed ${ }^{1}$ has shown that the eigenvectors of the matrix $M$ are

$$
\phi_{N}=\left\{\left[\ldots, \cos \frac{(i-1 / 2) \pi}{N}, \cos \frac{(i+1 / 2) \pi}{N}, \cos \frac{(i+3 / 2) \pi}{N}, \ldots\right]\right\}
$$

for $N=1,2, \ldots$ The eigenvalues of $M$ are

$$
\lambda_{N}=c\left\langle\frac{\sigma^{2}(\Delta x)^{2} / 4\left(\mu_{m}\right)^{2}}{0^{2}(\Delta x)^{2} / 1\left(\mu_{m}\right)^{2}+\tau_{N}}\right\rangle
$$

where the symbol \langle\rangle denotes a summation over all discrete directions,

$$
\left\langle x_{n}\right\rangle=\sum_{m=1}^{M} w_{m} x_{m},
$$


and

$$
\tau_{N}=\frac{1-\cos \frac{\pi}{N}}{1+\cos \frac{\pi}{N}}
$$

Alcouffe ${ }^{2}$ showed that his correction equation (5) with zero source can be written as

$$
\begin{aligned}
-\frac{D}{(\Delta x)^{2}} & \left(\phi_{0 i+3 / 2}^{k}-2 \phi_{0 i+1 / 2}^{k}+\phi_{0 i-1 / 2}^{k}\right) \\
& +\frac{\sigma_{R}}{4}\left(\phi_{0 i}^{k}+3 / 2+2 \phi_{0 i}^{k}+1 / 2+\phi_{0 i}^{k}-1 / 2\right) \\
& =\frac{2 D}{(\Delta x)^{2}}\left(\tilde{\phi}_{2 i}^{k}+3 / 2-2 \tilde{\phi}_{2 i}^{k}+1 / 2+\tilde{\phi}_{2 i-1 / 2}^{k}\right)
\end{aligned}
$$

where

$$
\tilde{\phi}_{2 i}^{k}+1 / 2=\sum_{m=1}^{M} \tilde{\psi}_{m i}+1 / 2 W_{m} P_{2}\left(\mu_{m}\right) \text {, and }
$$

where $\mathrm{P}_{2}\left(\mu_{\mathrm{m}}\right)$ is the second order Legendre polynomial. In the case of an infinite slah this system of equations can then be written as

$$
\phi_{0}^{k}=\tilde{A}_{2}^{k}
$$

The matrix $A$ has the eigenvectors $\left\{\phi_{N}\right\}$ with eigenvalues $\theta_{N}$ where,

$$
\theta_{N}=\frac{2 n_{N}}{n_{N}+1 / 2(1-c) \sigma(1+\cos \pi / N)}
$$

and 


$$
n_{N}=\frac{2 d}{\Delta x^{2}}(1-\cos \pi / N)
$$

Alcouffe also showed that

$$
\tilde{\phi}_{2}^{k}=B \phi_{0}^{k-1}
$$

where the matrix $B$ has eigenvalues

$$
B_{N}=c\left\langle\frac{\sigma^{2}(\Delta x)^{2} P_{0}\left(u_{m}\right) / 4\left(\mu_{111}\right)^{2}}{\sigma^{2}(\Delta x)^{2} / 4\left(\mu_{m}\right)^{2}+\tau_{N}}\right\rangle .
$$

Alcouffe then found that $B_{N} \theta_{N}<C$ for all $N=1,2, \ldots$

Equation (7) can be obtained from Eq. (5) by substituting a form of the discrete transport equation (2) along with the diamond difference equation (3). Taking the first order discrete moment of Eq. (2) yields

$$
\frac{\tilde{\phi}_{1 j}^{k}+1 / 2-\tilde{\phi}_{1 j}^{k}-1 / 2}{\Lambda x}+\sigma \tilde{\phi}_{0 i}^{k}=\sigma_{s} \phi_{0 i}^{k-1}+Q_{j} .
$$

Combining Eq. (16) with the same relationship from the $i+1$ cell, dividing by two and using Eq. (3) gives

$$
\frac{\tilde{\phi}_{1 i+1}^{k}-\tilde{\phi}_{1 i-1}^{k}}{\Delta x}+\frac{\pi}{2}\left(\tilde{\phi}_{0 i}^{k}+\tilde{\phi}_{0 i+1}^{k}\right)=\frac{\sigma_{\delta}}{2}\left(\phi_{0 i}^{k-1}+\phi_{0 i+1}^{k-1}\right)+\frac{1}{2}\left(Q_{j}+Q_{i+1}\right) .
$$

Rearranging Eq. (17) yields

$$
\begin{aligned}
\frac{\tilde{\phi}_{1 i+1}^{k}-\tilde{\phi}_{1 i-1}^{k}}{\Delta x} & \left(-\frac{\sigma_{R}}{2}-\frac{\sigma_{s}}{2}\right)\left(\tilde{\phi}_{0 i}^{k}+\tilde{\phi}_{0 i+1}^{k}\right)+\frac{\sigma_{s}}{2}\left(\phi_{0 i}^{k-1}+\phi_{0 i+1}^{k-1}\right) \\
& +\frac{1}{2}\left(Q_{i}+Q_{i+1}\right)
\end{aligned}
$$


which gives

$$
\begin{aligned}
\frac{\tilde{\phi}_{1+1}^{k}-\tilde{\phi}_{l i-1}^{k}=}{\Delta x} & -\frac{\sigma_{R}}{4}\left(\phi_{0 i}-1 / 2+2 \tilde{\phi}_{0 i}+1 / 2+\tilde{\phi}_{0 i}+3 / 2\right) \\
& -\frac{\sigma_{s}}{2}\left[\left(\tilde{\phi}_{0 i}-\phi_{0 i}^{k-1}\right)+\left(\tilde{\phi}_{0 i+1}-\phi_{0 i+1}^{k-1}\right)\right]+\frac{1}{2}\left(Q_{i}+Q_{j+1}\right)
\end{aligned}
$$

when Eq. (3) is used. Substituting Eq. (19) into Eq. (5) yields Eq. (7). Thus the correction equation (7) for the mesh-cornered synthetic method can be written in the form

$$
\phi_{0}^{k}=A^{\sim} \tilde{\phi}_{2}^{k}
$$

for an infinite slab with zero source where $A^{-}=A$. Thus the meshcornered synthetic method is stable for $c<1$.

\section{NUMERICAL RESULTS AND CONCLUSIONS}

A series of problems was run to determine the stability limits of the three rebalance methods discussed above.

A smoothing method has been invented by Rhoades which is designed to extend the stability limits of the mesh-centered synthetic (CES) method. With this method the rebalance factors, $\left\{f_{i}\right\}_{i=1, \ldots, I}$ are defined by

$$
f_{i}^{\prime}=\phi_{0 i}^{\prime k} / \tilde{\phi}_{0 i}^{k}
$$

where the prime indicates a rebalanced, unsmoothed flux gotten by solving Eq. (4). These mesh-centered rebalance factors are averaged to form mesh-cornered rebalance factors using 


$$
f_{i+1 / 2}^{\prime}=\frac{1}{2}\left(f_{i}^{\prime}+f_{i+1}^{\prime}\right) .
$$

Then the mesh-cornered rebalance factors are averaged to obtain smoothed mesh-centered rebalance factors using

$$
f_{i}=\frac{1}{2}\left(f_{i}^{\prime}-1 / 2+f_{i}^{\prime}+1 / 2\right) .
$$

Finally, these smoothed rebalance factors are used to find the meshcentered rebalanced, smoothed flux with

$$
\phi_{0 i}^{k}=f_{i} \tilde{\phi}_{0 i}^{k}
$$

The series of problems was run using the CES method both with and without smoothing. Also the problems were run using. the DOT ${ }^{4}$ conventional rebalance method both with and without damping. ${ }^{5}$ The mesh-cornered synthetic (MCS) and Alcouffe's SCS were also used.

The series of problems was run in two-dimensional slab geometry, which is illustrated in Fig. 1.

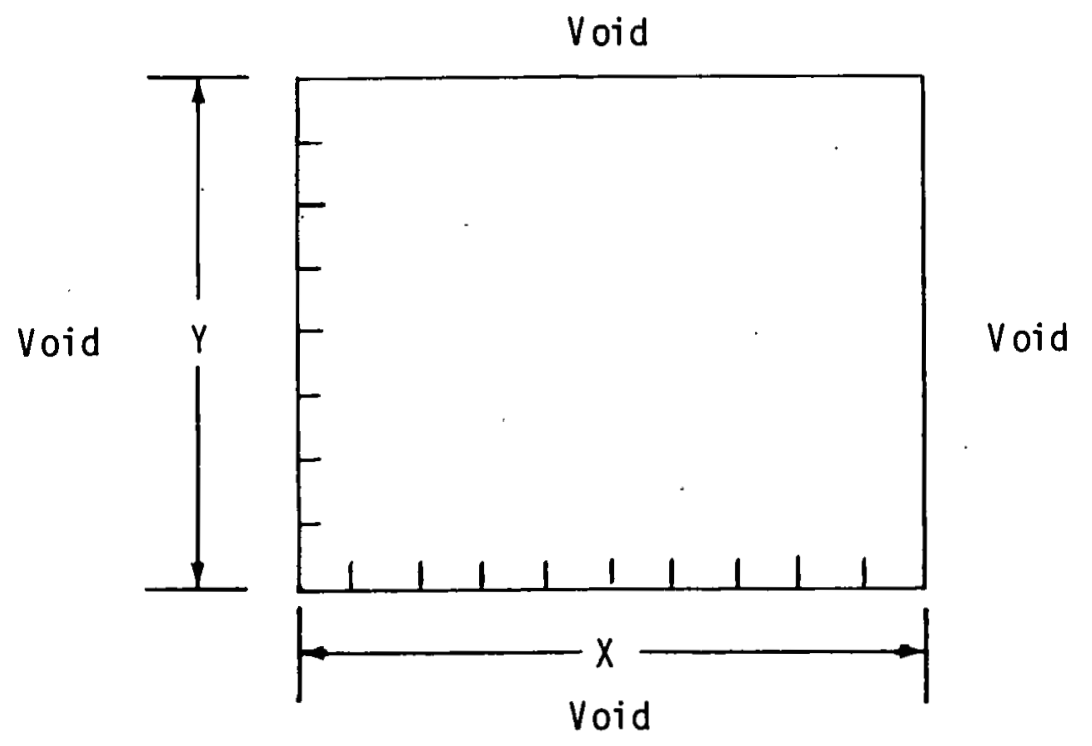

Fig. 1. X-Y Slab Geometry. 
All of the problems have constant mesh spacing with $\Delta x=\Delta y$. The total cross section, $\sigma=2.0 \mathrm{~cm}^{-1}$. A source is distributed throughout all of the mesh intervals. These P-O transport calculations were done using an S-6 quadrature set with the DOT code. Diamond differencing was used in the transport calculation.

There were two sets in the series of problems; the $C$ set and the $D X$ set. With the $C$ set $\sigma_{S}$ is varied which amounts to varying the scattering ratio since $\sigma$ is kept constant. In the $D X$ set $\Delta x=\Delta y$ is varied by changing the dimension of the problem, $R$, as seen in Fig. 1 . A description of both the $C$ set and the $D X$ set is in Table 1 .

Table 1. A description of the problem series

\begin{tabular}{ccccccl}
\hline & & & & & $(2 c-1) \sigma \Delta x$ & \\
Problem & $\sigma_{S}$ & $C$ & $R$ & $\Delta x$ & $\frac{d}{\Delta x}$ \\
\hline C2 & 1.2 & 0.6 & 8 & 1 & 0.1 & 0.166667 \\
C3 & 1.4 & 0.7 & 8 & 1 & 0.2 & 0.166667 \\
C4 & 1.6 & 0.8 & 8 & 1 & 0.3 & 0.166667 \\
C5 & 1.8 & 0.9 & 8 & 1 & 0.4 & 0.166667 \\
C6 & 2.0 & 1.0 & 8 & 1 & 0.5 & 0.166667 \\
DX1 & 2.0 & 1.0 & 6.66667 & 0.833333 & 0.416667 & 0.2 \\
DX2 & 2.0 & 1.0 & 4.44444 & 0.555556 & 0.277778 & 0.3 \\
DX3 & 2.0 & 1.0 & 3.33333 & 0.416667 & 0.208 & 0.4 \\
DX4 & 2.0 & 1.0 & 2.66667 & 0.333333 & 0.166667 & 0.5 \\
DX5 & 2.0 & 1.0 & 2.22222 & 0.277778 & 0.138889 & 0.6 \\
DX6 & 2.0 & 1.0 & 16.0 & 2.0 & 1.0 & 0.083333 \\
\hline
\end{tabular}

The number of iterations required for convergence for each of the five methods is listed in Table 2 .

The most obvious observation to be made is that Alcouffe's SCS gives identical results to the mesh-cornered synthetic (MCS) method. This supports the theoretical finding that there is no difference in the stability criterion between these two methods when diamond differencing is used in the transport calculation.

Using Reed's stability criterion, inequality (8), it is to be expected that the CES method would not converge for problems C3 through C6 and problem DX1. With the exception of problem $C 3$ this prediction holds true. In problem $0 \times 6$ the mesh width is equal to 4 mean free 
Table 2. Results with the six methods

\begin{tabular}{|c|c|c|c|c|c|c|c|c|}
\hline \multirow[b]{3}{*}{ Problem } & \multirow[b]{3}{*}{ C } & \multirow[b]{3}{*}{$\Delta x$} & \multicolumn{6}{|c|}{ Iterations to converge } \\
\hline & & & \multicolumn{2}{|c|}{$\begin{array}{l}\text { DOT } \\
\text { conventional rebalance }\end{array}$} & \multicolumn{2}{|c|}{$\begin{array}{c}\text { Mesh-centered } \\
\text { synthetic (CES) methods }\end{array}$} & \multicolumn{2}{|c|}{$\begin{array}{l}\text { Mesh- } \\
\text { cornered methods }\end{array}$} \\
\hline & & & $\begin{array}{l}\text { With } \\
\text { damping }\end{array}$ & $\begin{array}{l}\text { Without } \\
\text { damping }\end{array}$ & $\begin{array}{l}\text { With } \\
\text { smoothing }\end{array}$ & $\begin{array}{l}\text { Without } \\
\text { smoothing }\end{array}$ & $\begin{array}{l}\text { Synthetic } \\
\text { (MCS) }\end{array}$ & $\begin{array}{l}\text { Alcouffe's } \\
\quad(S C S)\end{array}$ \\
\hline $\begin{array}{l}C 2 \\
C 3 \\
C 4 \\
C 5 \\
C 6 \\
D \times 6 \\
D \times 1 \\
D \times 2 \\
D \times 3 \\
D \times 3 \\
D \times 4 \\
D \times 5\end{array}$ & $\begin{array}{l}0.6 \\
0.7 \\
0.8 \\
0.9 \\
1.0 \\
1.0 \\
1.0 \\
1.0 \\
1.0 \\
1.0 \\
1.0\end{array}$ & $\begin{array}{l}1.0 \\
1.0 \\
1.0 \\
1.0 \\
1.0 \\
2.0 \\
0.833333 \\
0.555556 \\
0.116667 \\
0.333333 \\
0.277778\end{array}$ & $\begin{array}{r}6 \\
6 \\
7 \\
8 \\
12 \\
16 \\
11 \\
8 \\
7 \\
7 \\
6\end{array}$ & $\begin{array}{r}8 \\
10 \\
14 \\
\star \\
\star \\
\star \\
\star \\
16 \\
11 \\
10 \\
10\end{array}$ & $\begin{array}{r}9 \\
13 \\
14 \\
12 \\
16 \\
23 \\
12 \\
12 \\
111 \\
7 \\
8\end{array}$ & $\begin{array}{r}44 \\
19 \\
\star \\
\star \\
\star \\
\star \\
\star \\
54 \\
16 \\
10 \\
9\end{array}$ & $\begin{array}{r}7 \\
7 \\
8 \\
9 \\
11 \\
14 \\
10 \\
9 \\
8 \\
8 \\
8\end{array}$ & $\begin{array}{r}7 \\
7 \\
8 \\
9 \\
11 \\
14 \\
10 \\
\cdot 9 \\
8 \\
8 \\
8\end{array}$ \\
\hline
\end{tabular}

paths. It is seen that the smoothing procedure is quite effective in expanding the stability limits of the CES method, but the procedure is usually inferior to the cornered methods.

The mesh-cornered methods are superior to DOT conventional rebalance without damping in all cases. However when DOT conventional rebalance is damped it is superior to the mesh-cornered methods in all of the cases studied except the case of $c=1$ and large mesh spacing. 


\section{LIST OF REFERENCES}

1. W. H. Reed, "The Effectiveness of Acceleration Techniques for Iterative Methods in Transport Theory," Nucl. Sci. Eng., 45, 245 (1971).

2. R. E. Alcouffe, "Diffusion Synthetic Acceleration Methods for the Diamond-Differenced Discrete-Ordinates Equations," Nucz. Sci: Eng., 64, 344 (1977).

3. J. E. Aul1, W. A. Rhoades, H. L. Dodds, "A Modified Approach to Diffusion Acceleration in Neutron Transport Problems," Trans. Am. Nucl. Soc., 32, 306 (1979).

4. W. A. Rhoades, D. B. Simpson, R. L. Childs, W. W. Engle, Jr., The DOT-IV Tho-Dimensional Discrete Ordinates Traneport Code with Space-Dependent Mesh and quadrature; ORNL/TM-6529 (1979).

5. W. A. Rhoades, R. L. Childs, W. W. Engle, Jr., "Comparison of Rebalance Stabilization Methods for Two-Dimensional Transport Calculations," Trans. Am. Nucl. Soc., 30 (1978). 


\section{THIS PAGE}

\section{WAS INTENTIONALLY \\ LEFT BLANK}


ORNL/TM-7097

\section{INTERNAL DISTRIBUTION}

1. L. S. Abbott

2. D. E. Bartine

3. R. L. Childs

4. W. W. Engle, Jr.

5. G. F. Flanagan

6. H. Goldstein (Consultant)

7. F. C. Maienschein

8-12. W. A. Rhoades

13. E. T. Toml inson

14. RSIC
15. P. Greebler (Consultant)

16. W. B. Loewenste in (Consultant)

17. R. Wilson (Consultant)

18-19. Central Research Library

20. ORNL Y-12 Technical Library Document Reference Section

21-22. Laboratory Records Department

23. Laboratory Records ORNL RC

24. ORNL Patent Office

25-28. EPD Reports Office

\section{EXTERNAL DISTRIBUTION}

29-30. Mr. John Au11, Jones Hall, Brevard College, Brevard, NC 28712.

31. Professor Julius Smith, Department of Mathematics, The University of Tennessee, Knoxville, Tennessee 37916.

32. Professor Vassilios Dougalis, Department of Mathematics, The University of Tennessee, Knoxville, Tennessee 37916.

33. Assistant Manager, Energy Research and Development, DOE, ORO. 34-60. Technical Information Center, P 0 Box 62, Oak Ridge, TN 37830. 